\title{
PROFUNDIDADE DE SEMEADURA E CRESCIMENTO INICIAL DE ESPÉCIES FORRAGEIRAS UTILIZADAS PARA COBERTURA DO SOLO
}

\author{
Depth of sowing and initial growth of forage species used for soil coverage \\ Leandro Pereira Pachecoํㅜ Fábio Ribeiro Pires², Fernando Pereira Monteiro ${ }^{3}$, \\ Sérgio Oliveira Procópio ${ }^{4}$, Renato Lara de Assis ${ }^{5}$, Fabiano André Petter ${ }^{6}$
}

\begin{abstract}
RESUMO
O uso do consórcio entre plantas de cobertura e culturas anuais, no Cerrado, tem sido prática cada vez mais difundida, pela possibilidade de implantação das forrageiras durante o desenvolvimento das culturas anuais, através da diferença de profundidade e sistema de semeadura. Objetivou-se, neste trabalho avaliar a emergência e algumas características agronômicas de quatro espécies de plantas de cobertura, em diferentes profundidades, visando ao seu emprego na consorciação e sobressemeadura em culturas anuais. O experimento foi conduzido em casa-de-vegetação, no delineamento experimental de blocos ao acaso, em arranjo fatorial $4 \times 7$, composto pelas plantas de cobertura Brachiaria brizantha, B. decumbens, B. ruziziensis e Panicum maximum cv. Tanzânia, e por seis profundidades de semeadura e um sistema de cobertura de sementes ( 0 sem cobertura, 0 com cobertura, $1,4,8,10$ e $15 \mathrm{~cm})$. As sementes foram semeadas em vasos e as plantas cultivadas por 40 dias. Avaliou-se o índice e o tempo de emergência, a altura de plantas, a fitomassa verde e seca da parte aérea, a área foliar, a fitomassa seca radicular e a densidade de comprimento radicular. O maior desenvolvimento das plantas estudadas foi detectado nas semeaduras até $1 \mathrm{~cm}$ de profundidade. $\mathrm{O} P$. maximum não apresentou aptidão para uso em consórcio com culturas anuais.Não se recomenda a semeadura das plantas de cobertura a partir de $10 \mathrm{~cm}$.
\end{abstract}

Termos para indexação: Sobressemeadura, plantio direto, integração lavoura-pecuária, Brachiaria spp., P. maximum.

\begin{abstract}
The use of the consortium between cover crops and annual crops in the Cerrado, is an increasingly widespread practice, because of the possibility of deployment of cover crops during the development of annual crops by the difference in depth and seeding system. The objective was to evaluate the emergency and some agronomic characteristics of four species of cover crops at different seeding depths, to use them in consortium and oversown in annual crops. The experiment was conducted in a greenhouse, and the experimental design of randomized blocks in factorial arranged $4 \mathrm{x} 7$, where it was four cover crops: Brachiaria brizantha, B. decumbens, B. ruziziensis and Panicum maximum cv. Tanzania, and six depths of sowing and a cover of seed system $(0 \mathrm{~cm}$ without any mulch, $0 \mathrm{~cm}$ with a mulch of soybean leaves, 1, 4, 8, 10 and $15 \mathrm{~cm})$. The cover crops were cropped in vase for 40 days. We evaluated emergence index, emergence time, plant height, green biomass and dry biomass of the above-ground part, leaf area, root dry biomass and root length density. The largest development of the cover crops was detected in the sowing up to $1 \mathrm{~cm}$ of depth. The $P$. maximum showed no ability to use in consortium with annual crops. The sowing of the cover crops from $10 \mathrm{~cm}$ is not recommended.
\end{abstract}

Index terms: Oversowing, no-till, crop-livestock integration, Brachiaria spp., P. maximum.

(Recebido em 29 de agosto de 2008 e aprovado em 11 de fevereiro de 2010)

\section{INTRODUÇÃO}

Sistemas consorciados entre culturas e plantas de cobertura, difundidos como integração lavoura-pecuária (ILP), têm demonstrado ser viáveis (Portes et al., 2000), constituindo-se em alternativa para viabilizar a sustentabilidade do sistema plantio direto (SPD) no Cerrado, por resultar em contribuição para a rotação/ sucessão de culturas e a manutenção de palhada no solo (Ceretta et al., 2002). Menezes \& Leandro (2004) apontam a introdução de plantas de cobertura no Cerrado como alternativa viável para cobrir o solo, principalmente as gramíneas, por apresentar maior resistência à decomposição da palha em relação às leguminosas, em razão da maior relação $\mathrm{C} / \mathrm{N}$.

Como modalidade de consórcio, o Sistema Santa-Fé (Kluthcouski \& Aidar, 2003) objetiva a produção de forragem para a entressafra, em solos corrigidos, em áreas destinadas à produção de grãos de culturas anuais. Para viabilizar o consórcio simultâneo, as plantas de cobertura

\footnotetext{
'Universidade Federal do Piauí/UFPI - Departamento de Agronomia - Campus Professora Cinobelina Elvas/CPCE - Rodovia BR 135 - Km 03 - Setor Planalto Horizonte -64900-000 - Bom Jesus, PI - leandroppacheco@gmail.com

2Universidade Federal do Espírito Santo/UFES - Centro Universitário Norte do Espírito Santo/CEUNES - São Mateus, ES

3Universidade de Rio Verde - Rio Verde, GO

${ }^{4}$ Empresa Brasileira de Pesquisa Agropecuária/Embrapa - Tabuleiros Costeiros - Aracaju, SE

${ }^{5}$ Instituto Federal de Educação, Ciência e Tecnologia - Iporá, GO

${ }^{6}$ Universidade Federal do Piauí/UFPI - Campus Professora Cinobelina Elvas/CPCE - Bom Jesus, PI
} 
precisam ter seu crescimento inicial retardado, para que a cultura anual consiga se sobressair nos estádios iniciais de seu estabelecimento. Além do uso de subdoses de herbicidas seletivos à cultura anual (Silva et al., 2005), a semeadura da planta de cobertura em consórcio, em maiores profundidades, mostra-se alternativa viável e capaz de favorecer o potencial competitivo da cultura anual consorciada (Kluthcouski \& Aidar, 2003). Em decorrência de ligeiro atraso na emergência, as plantas de cobertura ficam sombreadas, apresentando crescimento inicial mais lento, por possuir metabolismo $\mathrm{C}_{4}$ de fixação de $\mathrm{CO}_{2}$, característica que as torna muito exigentes por luz (Portes et al., 2000).

Essas evidências foram constatadas por Pacheco et al. (2009), trabalhando com Brachiaria brizantha em diferentes profundidades de semeadura, o qual observou sensível redução na velocidade de emergência, com o aumento da profundidade de deposição da semente. Oliveira et al. (1996) também encontraram resultados semelhantes, evidenciando que, quando suprimida pela maior profundidade de semeadura, distribuída misturada ao fertilizante, seu crescimento é reduzido, o que resultou em maiores produtividades na cultura do arroz, em consórcio simultâneo. Apesar dessas informações, existem poucos estudos sobre o desempenho inicial de plantas de cobertura, particularmente quanto à profundidade de semeadura ideal, ou seja, aquela que resulta em atraso na germinação suficiente para evitar interferência na cultura anual, sem, contudo, prejudicar a planta de cobertura.

Diferentemente do que ocorre com o milho, mesmo adotando-se medidas para supressão da planta de cobertura, a cultura da soja tem apresentado desempenho insatisfatório em consórcios simultâneos. Isso se dá devido a sua menor capacidade competitiva da soja em consórcio, e a ineficiência do uso de herbicidas graminicidas utilizados em subdose para supressão da planta de cobertura (Silva et al., 2005). A altura de corte da plataforma, por ocasião da colheita mecanizada da soja, é outro fator que dificulta a consorciação. Contudo, a sobressemeadura (a lanço) de plantas de cobertura, por ocasião da maturidade fisiológica da soja (início da desfolha: estádio $\mathrm{R}_{7}$ ), constitui-se em alternativa promissora na inclusão dessa cultura na ILP (Pacheco et al., 2008), proporcionando maior flexibilidade no cronograma operacional de produção, principalmente no processo de colheita de grãos.

O trabalho de Lara-Cabezas (2004), com sementes peletizadas de Pennisetum glaucum, aponta a sobressemeadura na soja como opção para produção de palhada e cobertura do solo e/ou produção de forragem, no período de seca (outono-inverno). Todavia, existem poucas informações que atestem sua eficiência, bem como apontem as plantas de cobertura mais indicadas para semeadura na superfície do solo.

Objetivou-se, neste trabalho, a emergência e algumas características agronômicas de quatro espécies de plantas de cobertura, em diferentes profundidades, visando ao seu emprego na consorciação e na sobressemeadura em culturas anuais.

\section{MATERIAL E MÉTODOS}

O experimento foi implantado em casa-de-vegetação da Universidade de Rio Verde, em Rio Verde, GO (Latitude $\mathrm{S}=17^{\circ} 48^{\prime}$, Longitude $\mathrm{W}=50^{\circ} 55^{\prime}$, Altitude $760 \mathrm{~m}$ ). Utilizouse solo classificado como Latossolo Vermelho Distroférrico para preenchimento dos vasos $\left(8 \mathrm{dm}^{3}\right)$. O solo, coletado na camada de $0-20 \mathrm{~cm}$, apresentou $\mathrm{pH}\left(\mathrm{CaCl}_{2}\right) 4,09 ; \mathrm{Ca}$, $\mathrm{Mg}, \mathrm{Al}, \mathrm{e} \mathrm{H}+\mathrm{Al}$ de 0,$06 ; 0,04 ; 0,05$ e 2,9 $\mathrm{cmol}_{\mathrm{c}} \mathrm{dm}^{-3}$, respectivamente; $\mathrm{K}$ e $\mathrm{P}$ com 17 e $0,30 \mathrm{mg} \mathrm{dm}^{-3}$, respectivamente; CTC e SB com 3,20 e $0,32 \mathrm{cmol}_{\mathrm{c}} \mathrm{dm}^{-3}$, respectivamente; V (\%) 9,88; M.O. 12,79 $\mathrm{g} \mathrm{kg}^{1}$; Areia, Silte e Argila com 310, 150 e $540 \mathrm{~g} \mathrm{~kg}^{1}$, respectivamente. O solo foi corrigido com calcário filler trinta dias antes da semeadura das plantas de cobertura, em dose proporcional à 2,5 $\mathrm{Mg} \mathrm{ha}^{-1}$, para alcançar saturação por base $(\mathrm{V} \%) \mathrm{de}$ $60 \%$. A adubação utilizada na ocasião da semeadura das plantas de cobertura foi de 2,0 $\mathrm{g} \mathrm{vaso}^{-1}$ (equivalente a 500 $\left.\mathrm{kg} \mathrm{ha}^{-1}\right)$ da fórmula 05:25:15 $\left(\mathrm{N}: \mathrm{P}_{2} \mathrm{O}_{5}: \mathrm{K}_{2} \mathrm{O}\right)$.

$\mathrm{O}$ delineamento experimental do experimento foi em blocos ao acaso, em arranjo fatorial 4 x 7, com quatro repetições, sendo quatro plantas de cobertura [Brachiaria brizantha (Hochst. ex A. Rich.) Stapf. cv. Marandu, Brachiaria decumbens Stapf., Brachiaria ruziziensis Germain \& Evrard. e Pannicum maximum Jacq. cv. Tanzânia], semeadas em seis profundidades e um sistema de cobertura de sementes [(sementes depositadas na superfície solo (zero $\mathrm{cm}$ ), sem qualquer cobertura sobre as mesmas; sementes depositadas na superfície solo (zero $\mathrm{cm})$, cobertas por folhas de soja e uma fina camada de solo para evitar sua remoção pelo vento; e nas profundidades de semeadura de $1 ; 4 ; 8 ; 10$ e 15 cm]. Para calibração das profundidades de semeadura subsuperficiais foram pesados $8 \mathrm{~kg}$ de solo e acondicionados em vasos, imediatamente após a calagem; após trinta dias, com auxílio de régua graduada, extraiu-se todo o solo acima da profundidade de semeadura requerida para cada tratamento; em seguida, as sementes foram depositadas e, imediatamente, cobertas com o volume do solo extraído anteriormente do vaso.

No dia 23/10/2005 foram semeadas 20 sementes vaso $^{-1}$, no qual, aos 14 dias após a semeadura (DAS), efetuou-se desbaste, deixando-se duas plantas por vaso para todas as espécies avaliadas, as quais foram cultivadas 
até 40 DAS. Os vasos foram irrigados por microaspersão com turno de rega automático.

Determinou-se o índice de emergência (IE) das plantas de cobertura nas diferentes profundidades de semeadura, em que o total de plantas emergidas a $1 \mathrm{~cm}$ de profundidade foi considerado o padrão $=1$. Nos demais tratamentos, o IE foi calculado em relação ao número de plantas emergidas no tratamento padrão, em que: IE = número de plantas emergidas no tratamento $\mathrm{X}$ / número de plantas emergidas no tratamento padrão estabelecido para cada planta de cobertura - adaptado de Portella et al. (1997). O número de plantas emergidas foi contabilizado diariamente até aos 14 DAS das plantas de cobertura, período a partir do qual o número de plantas emergidas se manteve constante. Determinou-se também o tempo de emergência (TE) das plantas em cada profundidade de semeadura, de acordo com metodologia proposta por Miranda \& Ferraz (1999). Essa avaliação foi realizada medindo-se o tempo gasto, em dias, para emergência de $50 \%$ do número total de plantas por vaso, em que considerou-se como emergida, a plântula que apresentou a folha primária exposta além da superfície do solo.

Aos 20 e 40 DAS, foi determinada a altura de plantas (AP), tomando-se como base para a medição o colo da planta até a extremidade do dossel. Aos 40 DAS foram avaliadas a área foliar (AF), as fitomassas verde (FV) e seca (FS) da parte aérea, fitomassa seca de raízes (FSR) e a densidade de comprimento radicular (DCR).

A AF foi obtida indiretamente por meio do produto das medidas de comprimento e largura de todas as folhas de cada planta, com auxílio de régua, multiplicado por 0,79 ; 0,76; 0,78 e 0,57 para B. brizantha, B. decumbens, $B$. ruziziensis e $P$. maximum, respectivamente. Esses valores representam o coeficiente, usado como fator de ajuste da forma do limbo da folha de cada espécie (comprimento e largura) em relação à sua área real, na estimativa da AF. Esse índice foi obtido por meio do produto das dimensões da folha dividido por sua área real, obtida eletronicamente no programa computacional Quant Root v. 1.0, após digitalização (Pacheco et al., 2009).

Para avaliação da FV e FS da parte aérea coletaramse as duas plantas inteiras, seccionadas rente ao solo e imediatamente pesadas. Após, foram secas em estufa, com circulação forçada de ar, por 72 horas a $65^{\circ} \mathrm{C}$, e pesadas, obtendo-se a FS.

A FSR foi obtida após a retirada, lavagem e secagem em estufa, com circulação forçada de ar, por 72 horas a $65^{\circ} \mathrm{C}$, de todo o sistema radicular contido no vaso, seguido de pesagem. Determinou-se também a DCR (Pacheco et al., 2009), dividindo-se o comprimento radicular total, obtido após digitalização das raízes e quantificação pelo programa Quant Root v. 1.0, pelo volume total do vaso.

Os dados foram submetidos à análise de variância e as médias dos tratamentos foram comparadas pelo teste Tukey, a $5 \%$ de significância.

\section{RESULTADOS E DISCUSSÃO}

O Índice de Emergência (IE) a $8 \mathrm{~cm}$ de profundidade foi estatisticamente diferente da profundidade de $1 \mathrm{~cm}$ para todas as espécies (Tabela 1). Isso evidencia que a semeadura em profundidades maiores pode prejudicar o estande de plantas, necessitando, portanto, de aumento da densidade de sementes para se alcançar o estande ideal da planta de cobertura. No entanto, essa medida implica em aumento no custo de produção, podendo inviabilizar o uso de semeaduras mais profundas para retardar a emergência das plantas de cobertura na ILP. Para se obter o estande equivalente entre as profundidades 1 e $8 \mathrm{~cm}$, seria necessário multiplicar a quantidade inicial de sementes por 2,7;2,2 e 6,6 das espécies $B$. brizantha, $B$. decumbens e $B$. ruziziensis, respectivamente.

$\mathrm{Na}$ profundidade de $8 \mathrm{~cm}$, conseguiu-se IE superior a 0,37 para as $B$. brizantha e $B$. decumbens, embora menor comparado a $1 \mathrm{~cm}$ de profundidade, indicando ser a profundidade limite para seu cultivo em consórcio. Isso se dá, em razão das braquiárias perfilharem após a colheita da cultura anual, o que compensaria a defasagem no estande (Portes et al., 2000).

$\mathrm{Na}$ semeadura em superfície $(0 \mathrm{~cm})$, a presença de cobertura sobre as sementes não alterou o IE para as braquiárias, exceto a $B$. ruziziensis. Os IE obtidos permitem afirmar que, o uso da sobressemeadura de forrageiras em culturas anuais como a soja apresenta viabilidade, possibilitando satisfatório estabelecimento de estande na área. O P. maximum apresentou, no tratamento com cobertura das sementes, IE próximo ao obtido à $1 \mathrm{~cm}$ de profundidade. Por outro lado, essa planta de cobertura foi a mais sensível quanto ao aumento de profundidade de semeadura, não apresentando emergência nos tratamentos a partir de $8 \mathrm{~cm}$ de profundidade. Altmann (2001) aponta a cobertura exercida pelas folhas da cultura anual, sobrepostas às sementes das plantas de cobertura, como requisito essencial à emergência dessas últimas, pois aumentam o contato com o solo e, consequentemente, auxiliam na proteção contra a desidratação das sementes em caso de estresse hídrico. Pacheco et al. (2008), também encontrou viabilidade no uso da sobressemeadura em soja, na região dos cerrados. Todavia, os melhores resultados foram obtidos principalmente com milheto (Pennisetum glaucum), capim-pé-de-galinha [Eleusine coracana $(L$. Gaertn] e braquiária (B. ruziziensis). Essas espécies 
apresentaram maior emergência de plantas em sobressemeadura, maior produção de biomassa e maiores taxas de cobertura do solo na entressafra.

As espécies B. brizantha e B. decumbens apresentaram os maiores IE entre as plantas de cobertura avaliadas, registrando emergência mesmo quando as sementes foram semeadas a $10 \mathrm{~cm}$ de profundidade. A rusticidade dessas espécies, já relatadas por Kluthcouski \& Aidar (2003), possivelmente, contribuiu para tais resultados. Além disso, o maior tamanho das sementes das espécies do gênero Brachiaria em relação ao $P$. maximum, pode ser outro fator decisivo na emergência de plântulas, pois a maior quantidade de material de reservas (proteínas e carboidratos) resulta, teoricamente, em maior energia para a emergência (Alves et al., 2005).

Quanto ao tempo de emergência (TE), houve atraso a partir da semeadura a $10 \mathrm{~cm}$ para a $B$. brizantha e $8 \mathrm{~cm}$ de profundidade para as demais espécies. Porém, o atraso foi de 1 a 3 dias, tempo insuficiente, do ponto de vista prático, para favorecer a cultura anual (Tabela 1). No entanto, ressalta-se que no experimento foi utilizado solo peneirado e, portanto, desestruturado, o que pode ter facilitado a emergência em profundidades maiores. Em condições de campo, a maior densidade do solo incrementa a resistência à emergência das plântulas (Modolo et al., 2008); nessa situação, pode-se esperar que o efeito do aumento da profundidade de semeadura na emergência seja mais pronunciado, refletindo-se em maior defasagem no estabelecimento da planta de cobertura em relação à cultura anual. Oliveira et al. (1996), trabalhando com braquiárias, também observaram retardamento na emergência de plantas em função da profundidade de semeadura, sendo que a distribuição das sementes a 10 $\mathrm{cm}$ proporcionou atraso em torno de cinco dias na emergência das plântulas, suficiente para defasá-la em relação às culturas anuais consorciadas. Não foram detectadas diferenças entre as espécies avaliadas, dentro de cada profundidade, exceto para a B. ruziziensis a $8 \mathrm{~cm}$.

A AP é outro fator essencial para se definir o potencial de competição da planta de cobertura sobre a cultura anual. Observou-se, principalmente aos 20 DAS, que o aumento da profundidade de semeadura, resultou em redução na AP das braquiárias, exceto a $B$. decumbens, em mais de $50 \%$, notadamente a partir de $8 \mathrm{~cm}$, comparado a $1 \mathrm{~cm}$ de profundidade (Tabela 2). Na semeadura a zero $\mathrm{cm}$, houve tendência de aumento da AP com a presença de cobertura vegetal sobre as sementes, devido, provavelmente, à maior umidade do solo e ao contato da semente com o substrato (Portella et al., 1997), condições que favorecem a velocidade de emergência.

Tabela 1 - Índice de emergência e tempo de emergência das plantas de cobertura, em função da profundidade de deposição da semente.

\begin{tabular}{|c|c|c|c|c|c|c|c|}
\hline \multirow{2}{*}{ Espécie } & \multicolumn{7}{|c|}{ Profundidade $(\mathrm{cm})$} \\
\hline & 0 & $0 \mathrm{cob}$ & 1 & 4 & 8 & 10 & 15 \\
\hline \multicolumn{8}{|c|}{ Índice de emergência * } \\
\hline B. brizantha & $0,73 \mathrm{ABb}$ & $0,72 \mathrm{ABb}$ & $1,00 \mathrm{Aa}$ & $0,82 \mathrm{Aab}$ & $0,37 \mathrm{Ac}$ & 0,16 Acd & $0,00 \mathrm{Ad}$ \\
\hline B. decumbens & $0,58 \mathrm{Bb}$ & $0,39 \mathrm{Cb}$ & $1,00 \mathrm{Aa}$ & $0,80 \mathrm{Aa}$ & $0,45 \mathrm{Ab}$ & $0,11 \mathrm{Ac}$ & $0,00 \mathrm{Ac}$ \\
\hline B. ruziziensis & $0,78 \mathrm{Ab}$ & $0,55 \mathrm{BCc}$ & $1,00 \mathrm{Aa}$ & 0,93 Aab & $0,15 \mathrm{Bd}$ & $0,00 \mathrm{Ad}$ & $0,00 \mathrm{Ad}$ \\
\hline P. maximum & $0,57 \mathrm{Bb}$ & $0,88 \mathrm{Aa}$ & $1,00 \mathrm{Aa}$ & $0,81 \mathrm{Aa}$ & $0,00 \mathrm{Bc}$ & $0,00 \mathrm{Ac}$ & $0,00 \mathrm{Ac}$ \\
\hline C.V (\%) & \multicolumn{7}{|c|}{20,11} \\
\hline \multicolumn{8}{|c|}{ Tempo de emergencia (dias)** } \\
\hline B. brizantha & 7,75 Aa & $8,25 \mathrm{Aab}$ & $8,50 \mathrm{Aabc}$ & 9,50 Aabc & 10,50 Aabc & $10,75 \mathrm{Ac}$ & $* * *$ \\
\hline B. decumbens & $8,75 \mathrm{Aab}$ & 7,50 Aa & $7,25 \mathrm{Aa}$ & $8,50 \mathrm{Aab}$ & $9,75 \mathrm{Bb}$ & $10,15 \mathrm{Ab}$ & $* * *$ \\
\hline B. ruziziensis & $9,25 \mathrm{Aa}$ & $8,50 \mathrm{Aa}$ & 7,50 Aa & $8,50 \mathrm{Aa}$ & $12,25 \mathrm{Ab}$ & $* * *$ & $* * *$ \\
\hline P. maximum & $9,00 \mathrm{Aa}$ & $7,50 \mathrm{Aa}$ & $7,00 \mathrm{Aa}$ & $8,50 \mathrm{Aa}$ & $* * *$ & $* * *$ & $* * *$ \\
\hline C.V $(\%)$ & \multicolumn{7}{|c|}{12,09} \\
\hline $\begin{array}{l}\text { Médias seguidas d } \\
\text { Padrão: o total de } \\
\text { essa profundidade } \\
\text { ' Índice obtido p } \\
\end{array}$ & $\begin{array}{l}\text { esma letra, } \\
\text { ntas emerg }\end{array}$ & $1 \mathrm{~cm} \mathrm{de}$ & didade foi & $\begin{array}{l}\text { Is nas linhas } \\
\text { siderado } 1,00 \\
\text { as emergidas }\end{array}$ & $\begin{array}{l}\text { diferem ent } \\
\text { s demais val }\end{array}$ & $\begin{array}{l}\text { pelo teste d } \\
\text { oram obtide } \\
\text { meadura. }\end{array}$ & $\begin{array}{l}\text { ukey, a } 5 \\
\text { em relaçã }\end{array}$ \\
\hline
\end{tabular}

Ciênc. agrotec., Lavras, v. 34, n. 5, p. 1211-1218, set./out., 2010 
Tabela 2 - Altura de plantas (cm) das plantas de cobertura do solo, aos 20 e 40 dias, após semeadura em função da profundidade de deposição da semente.

\begin{tabular}{|c|c|c|c|c|c|c|c|}
\hline \multirow{2}{*}{ Espécie } & \multicolumn{7}{|c|}{ Profundidade de semeadura $(\mathrm{cm})$} \\
\hline & 0 & $0 \mathrm{cob}$ & 1 & 4 & 8 & 10 & 15 \\
\hline \multicolumn{8}{|c|}{20 dias após a semeadura } \\
\hline B. brizantha & $12,13 \mathrm{Abc}$ & 16,50 Bab & $21,00 \mathrm{Aa}$ & $15,94 \mathrm{Bab}$ & $8,00 \mathrm{Bcd}$ & 3,05 Ade & $0,00 \mathrm{Ae}$ \\
\hline B. decumbens & $15,00 \mathrm{Ab}$ & $23,45 \mathrm{Aa}$ & $20,56 \mathrm{Aab}$ & $21,44 \mathrm{Aa}$ & $15,03 \mathrm{Ab}$ & $3,85 \mathrm{Ac}$ & $0,00 \mathrm{Ac}$ \\
\hline B. ruziziensis & $16,50 \mathrm{Ab}$ & $21,00 \mathrm{Aab}$ & $22,50 \mathrm{Aa}$ & $20,88 \mathrm{Aab}$ & $4,78 \mathrm{Bc}$ & $0,00 \mathrm{Ac}$ & $0,00 \mathrm{Ac}$ \\
\hline P. maximum & $8,20 \mathrm{Bb}$ & $16,25 \mathrm{Ba}$ & $15,13 \mathrm{Ba}$ & $15,50 \mathrm{Ba}$ & $0,00 \mathrm{Cc}$ & $0,00 \mathrm{Ac}$ & $0,00 \mathrm{Ac}$ \\
\hline C.V $(\%)$ & & & & 24,00 & & & \\
\hline \multicolumn{8}{|c|}{40 dias após a semeadura } \\
\hline B. brizantha & $40,56 \mathrm{Aab}$ & $40,13 \mathrm{Bab}$ & $47,06 \mathrm{Aa}$ & $39,31 \mathrm{Bab}$ & $30,35 \mathrm{Bb}$ & $8,83 \mathrm{Bc}$ & $0,00 \mathrm{Ac}$ \\
\hline B. decumbens & $28,83 \mathrm{Bb}$ & $53,93 \mathrm{Aa}$ & $49,00 \mathrm{Aa}$ & $53,88 \mathrm{Aa}$ & 46,38 Aa & $19,63 \mathrm{Ab}$ & $0,00 \mathrm{Ac}$ \\
\hline B. ruziziensis & 44,63 Aab & 50,81 Aba & $32,19 \mathrm{Bc}$ & $37,75 \mathrm{Bbc}$ & $18,78 \mathrm{Cd}$ & $0,00 \mathrm{Be}$ & $0,00 \mathrm{Ae}$ \\
\hline P. maximum & $32,00 \mathrm{Bb}$ & 47,50 Aba & $45,44 \mathrm{Aa}$ & 43,94 Bab & $0,00 \mathrm{Dc}$ & $0,00 \mathrm{Bc}$ & $0,00 \mathrm{Ac}$ \\
\hline C.V $(\%)$ & & & & 19,29 & & & \\
\hline
\end{tabular}

Médias seguidas de mesma letra, maiúscula nas colunas e minúsculas nas linhas, não diferem entre si, pelo teste de Tukey, a 5\%.

O P. maximum e a $B$. brinzatha apresentaram, em geral, as menores médias em AP, aos 20 e 40 DAS, e a $B$. decumbens, as maiores, superiores a $46 \mathrm{~cm}$ aos 40 DAS, quando semeada a $8 \mathrm{~cm}$ de profundidade. Esses resultados indicam que a semeadura em maiores profundidades é parcialmente eficaz na redução da AP, o que pode estar associado à rusticidade, apresentada pelas espécies de plantas de cobertura avaliadas. Caso algum fator interfira no crescimento inicial da cultura anual em consórcio, as plantas de cobertura tendem a competir mais severamente, podendo provocar prejuízos na produtividade da cultura principal.

$\mathrm{Na}$ avaliação de área foliar (AF) das plantas de cobertura, as braquiárias foram pouco influenciadas pelo aumento da profundidade de semeadura, exceto a ruziziensis, que em superfície sem presença de cobertura vegetal sobre as sementes, teve o melhor desempenho (Tabela 3). Para a B. brizantha e a $B$. decumbens, somente a partir de $10 \mathrm{~cm}$ de profundidade, detectou-se redução da AF, por serem espécies de alta agressividade no crescimento da parte aérea. Entretanto, Portes et al. (2000), trabalhando com o crescimento de braquiárias, observou que a AF dos tratamentos submetidos ao consórcio foi menor comparada aos cultivos solteiros, durante os ciclos de diferentes culturas anuais. Esses resultados reforçam a necessidade de sementes sadias para o plantio da cultura anual, propiciando maiores condições de estabelecimento de plantas e menor interferência na sua produtividade.
O P. maximum apresentou, em geral, os maiores valores de $\mathrm{AF}$ até a profundidade de $4 \mathrm{~cm}$, por ser uma espécie com alto potencial de crescimento, e consequentemente, maior risco para a cultura anual em consórcio. Portanto, diante desses resultados, e considerando a área foliar um importante indicativo da capacidade de interceptação de radiação, sombreamento e realização de fotossíntese (Portes et al., 2005), não se recomenda o emprego do $P$. maximum em cultivos consorciados simultâneos.

Observou-se efeito significativo do aumento da profundidade de semeadura no acúmulo de FV e FS, mesmo quando semeado a $4 \mathrm{~cm}$ (Tabela 3). Em algumas forrageiras, a semeadura em superfície resultou em maiores valores de fitomassa, possivelmente, devido à maior velocidade no estabelecimento de plantas. As B. brizantha, B. decumbens e $B$. ruziziensis apresentaram a maior capacidade de produção de $\mathrm{FS}$ até $8 \mathrm{~cm}$ de profundidade, exceto quando semeado em superfície com presença de cobertura e a $1 \mathrm{~cm}$ de profundidade, mostrando ser uma espécie com maior capacidade competitiva com a cultura anual em consórcio. Esse comportamento pode ser ainda mais intensificado, à medida em que se aumenta o tempo de convivência entre as espécies em consórcio, o que torna necessário o uso de herbicidas em subdoses para suprimir seu crescimento. Silva et al. (2004) observou viabilidade no uso de herbicidas em subdoses no consórcio entre $B$. brizantha e soja, aplicado aos 21 dias após a emergência da cultura. A $B$. 
ruziziensis apresentou desempenho satisfatório quando semeada em superfície, corroborando Pacheco et al. (2008), em que essa forrageira destacou-se na capacidade de germinação superficial, e por isso, sua indicação como espécie de interesse para a sobressemeadura.

A produção de fitomassa é um dos principais parâmetros avaliados em espécies plantas de cobertura direcionadas à ILP (Pacheco et al., 2008). Elevadas produções de FV são desejáveis quando o sistema de cultivo contempla a introdução de bovinos na área para pastejo, notadamente quando a recuperação do dossel da planta de cobertura, após colheita da cultura principal, ocorre em curto período de tempo (Garcia et al., 2004). Além disso, as plantas em desenvolvimento promovem a cobertura e a proteção do solo contra o processo erosivo, como descrito por Kluthcouski \& Aidar (2003).

A FSR e DCR apresentaram redução com o aumento da profundidade de semeadura, efeito que, de modo geral, intensificou-se a partir de $8 \mathrm{~cm}$ de profundidade (Tabela 4). O P. maximum mostrou ser mais sensível quanto ao crescimento radicular, comparado às espécies do gênero Brachiaria, comprovando ser uma espécie que não tolera cultivos em maiores profundidades.

As braquiárias, principalmente a $B$. ruziziensis, apresentaram elevado crescimento radicular, o que pode resultar em melhores condições de desenvolvimento durante o período de ausência de chuvas na entressafra. Menezes \& Leandro (2004), avaliando o crescimento de plantas de coberturas, a B. ruziziensis e o P. glaucum destacaram-se no acúmulo de fitomassa, correlacionando com o elevado crescimento radicular dessas espécies. A zero $\mathrm{cm}, B$. decumbens e $B$. ruziziensis apresentaram aumento significativo na DCR quando suas sementes foram cobertas com folhas de soja. Isso indica que a sobressemeadura de forrageiras na soja apresenta-se como alternativa viável na formação de palhada para o plantio direto e forragem para a entressafra, principalmente para a $B$. ruziziensis, cujo desempenho em superfície foi sempre superior ou igual às demais plantas de cobertura, em todas as variáveis analisadas.

Tabela 3 - Área foliar (AF), fitomassa verde (FV) e seca (FS) da parte aérea das plantas de cobertura, em função da profundidade de deposição da semente.

\begin{tabular}{|c|c|c|c|c|c|c|c|}
\hline \multirow{2}{*}{ Espécie } & \multicolumn{7}{|c|}{ Profundidade de semeadura $(\mathrm{cm})$} \\
\hline & 0 & $0 \mathrm{cob}$ & 1 & 4 & 8 & 10 & 15 \\
\hline \multicolumn{8}{|c|}{ Área foliar $\left(\mathrm{cm}^{2}\right.$ planta $\left.^{-1}\right)$} \\
\hline B. brizantha & $287,38 \mathrm{Ba}$ & $209,52 \mathrm{Ca}$ & $329,11 \mathrm{Ba}$ & $219,48 \mathrm{Ba}$ & $225,50 \mathrm{Ba}$ & $39,64 \mathrm{Ab}$ & $0,00 \mathrm{Ab}$ \\
\hline B. decumbens & $198,23 \mathrm{Bab}$ & $235,63 \mathrm{Ca}$ & $165,80 \mathrm{Cab}$ & $274,02 \mathrm{Ba}$ & $263,99 \mathrm{ABa}$ & $63,68 \mathrm{Abc}$ & $0,00 \mathrm{Ac}$ \\
\hline B. ruziziensis & $583,09 \mathrm{Aa}$ & $407,60 \mathrm{Bb}$ & $274,63 \mathrm{Bb}$ & $319,68 \mathrm{ABb}$ & $349,38 \mathrm{Ab}$ & $0,00 \mathrm{Ac}$ & $0,00 \mathrm{Ac}$ \\
\hline P. maximum & $273,24 \mathrm{Bc}$ & $582,21 \mathrm{Aa}$ & $439,21 \mathrm{Ab}$ & $395,76 \mathrm{Abc}$ & $0,00 \mathrm{Cd}$ & $0,00 \mathrm{Ad}$ & $0,00 \mathrm{Ad}$ \\
\hline C.V (\%) & \multicolumn{7}{|c|}{30,14} \\
\hline \multicolumn{8}{|c|}{ Fitomassa verde $\left(\mathrm{g}_{\text {planta }}{ }^{-1}\right)$} \\
\hline B. brizantha & 9,07 Bab & 6,69 Cab & $10,9 \mathrm{Ba}$ & $6,54 \mathrm{Cab}$ & $5,70 \mathrm{Bb}$ & $0,90 \mathrm{Ac}$ & $0,00 \mathrm{Ac}$ \\
\hline B. decumbens & $5,22 \mathrm{Cb}$ & $12,28 \mathrm{Ba}$ & $5,43 \mathrm{Cb}$ & $10,64 \mathrm{Ba}$ & $10,27 \mathrm{Aa}$ & $1,50 \mathrm{Abc}$ & $0,00 \mathrm{Ac}$ \\
\hline B. ruziziensis & $19,08 \mathrm{Aa}$ & $13,05 \mathrm{Bb}$ & 7,70 BCc & $9,43 \mathrm{BCbc}$ & 8,58 ABbc & $0,00 \mathrm{Ad}$ & $0,00 \mathrm{Ad}$ \\
\hline P. maximum & $11,57 \mathrm{Bb}$ & $21,72 \mathrm{Aa}$ & $15,62 \mathrm{Ab}$ & $14,49 \mathrm{Ab}$ & $0,00 \mathrm{Cc}$ & $0,00 \mathrm{Ac}$ & $0,00 \mathrm{Ac}$ \\
\hline C.V (\%) & & & & 28,90 & & & \\
\hline \multicolumn{8}{|c|}{ Fitomassa seca $\left(\right.$ g planta $\left.^{-1}\right)$} \\
\hline B. brizantha & $1,63 \mathrm{Ba}$ & $1,17 \mathrm{Cab}$ & $2,15 \mathrm{Aa}$ & 1,19 Bab & $1,19 \mathrm{Aab}$ & $0,15 \mathrm{Abc}$ & $0,00 \mathrm{Ac}$ \\
\hline B. decumbens & 1,19 Bab & $1,54 \mathrm{Cab}$ & 1,08 Babc & 1,85 Aba & $1,07 \mathrm{Aa}$ & $0,49 \mathrm{Abc}$ & $0,00 \mathrm{Ac}$ \\
\hline B. ruziziensis & $3,20 \mathrm{Aa}$ & 2,48 Bab & $1,38 \mathrm{Bbc}$ & $1,89 \mathrm{ABbc}$ & 1,05 Acd & $0,00 \mathrm{Ad}$ & $0,00 \mathrm{Ad}$ \\
\hline P. maximum & $1,88 \mathrm{Bb}$ & $3,75 \mathrm{Aa}$ & $2,23 \mathrm{Ab}$ & $2,08 \mathrm{Ab}$ & $0,00 \mathrm{Bc}$ & $0,00 \mathrm{Ac}$ & $0,00 \mathrm{Ac}$ \\
\hline C.V $(\%)$ & & & & 39,30 & & & \\
\hline
\end{tabular}

Médias seguidas de mesma letra, maiúscula nas colunas e minúsculas nas linhas, não diferem entre si, pelo teste de Tukey, a 5\%. 
Tabela 4 - Fitomassa seca de raízes (FSR) e densidade de comprimento radicular (DCR) das plantas de cobertura, em função da profundidade de deposição da semente.

\begin{tabular}{|c|c|c|c|c|c|c|c|}
\hline \multirow{2}{*}{ Plantas de cobertura } & \multicolumn{7}{|c|}{ Profundidade de deposição da semente $(\mathrm{cm})$} \\
\hline & 0 & $0 \mathrm{cob}$ & 1 & 4 & 8 & 10 & 15 \\
\hline \multicolumn{8}{|c|}{ FSR (g planta $\left.{ }^{-1}\right)$} \\
\hline B. brizantha & $1,37 \mathrm{ABab}$ & $1,05 \mathrm{BCbc}$ & $2,24 \mathrm{Aa}$ & $1,16 \mathrm{Babc}$ & $0,71 \mathrm{ABbc}$ & $0,59 \mathrm{Abc}$ & $0,00 \mathrm{Ac}$ \\
\hline B. decumbens & $0,88 \mathrm{Bab}$ & $0,85 \mathrm{Cab}$ & $1,33 \mathrm{Ba}$ & $1,33 \mathrm{Ba}$ & $0,92 \mathrm{Aab}$ & 0,19 Aab & $0,00 \mathrm{Ab}$ \\
\hline B. ruziziensis & $2,17 \mathrm{Aa}$ & $2,27 \mathrm{Aa}$ & $2,62 \mathrm{Aa}$ & $2,38 \mathrm{Aa}$ & $0,42 \mathrm{ABb}$ & $0,00 \mathrm{Ab}$ & $0,00 \mathrm{Ab}$ \\
\hline P. maximum & $0,97 \mathrm{Bab}$ & $1,81 \mathrm{Aba}$ & $1,80 \mathrm{Ba}$ & $1,13 \mathrm{Bab}$ & $0,00 \mathrm{Bb}$ & $0,00 \mathrm{Ab}$ & $0,00 \mathrm{Ab}$ \\
\hline C.V $(\%)$ & \multicolumn{7}{|c|}{$49,00 \%$} \\
\hline \multicolumn{8}{|c|}{ DCR $\left(\mathrm{cm} \mathrm{cm}^{-3}\right.$ de solo $)$} \\
\hline B. brizantha & $0,68 \mathrm{Aab}$ & $0,89 \mathrm{Cab}$ & $1,10 \mathrm{Ba}$ & $0,96 \mathrm{Bab}$ & $0,40 \mathrm{ABab}$ & $0,15 \mathrm{Aab}$ & $0,00 \mathrm{Ab}$ \\
\hline B. decumbens & $0,73 \mathrm{Ab}$ & $2,48 \mathrm{Aa}$ & $0,88 \mathrm{Bb}$ & $0,87 \mathrm{Bb}$ & $0,75 \mathrm{Ab}$ & $0,17 \mathrm{Ab}$ & $0,00 \mathrm{Ab}$ \\
\hline B. ruziziensis & $1,07 \mathrm{Abc}$ & $2,15 \mathrm{Aba}$ & 1,89 Aab & 1,94 Aab & $0,21 \mathrm{ABcd}$ & $0,00 \mathrm{Ad}$ & $0,00 \mathrm{Ad}$ \\
\hline P. maximum & $0,59 \mathrm{Ab}$ & $1,62 \mathrm{Ba}$ & $0,84 \mathrm{Bab}$ & $0,76 \mathrm{Bab}$ & $0,00 \mathrm{Bb}$ & $0,00 \mathrm{Ab}$ & $0,00 \mathrm{Ab}$ \\
\hline C.V (\%) & & & & $59,09 \%$ & & & \\
\hline
\end{tabular}

Médias seguidas de mesma letra, maiúscula nas colunas e minúsculas nas linhas, não diferem entre si, pelo teste de Tukey, a 5\%.

Apesar do benefício decorrente da presença de maior densidade de raízes, em se tratando da espécie planta de cobertura, essa situação pode representar um fator de competição com a cultura anual, justamente pela ocupação de maior espaço físico no solo e, consequentemente, maior extração de água e nutrientes. Se isso ocorrer em camadas mais superficiais, em que o solo normalmente está corrigido e fertilizado, e havendo disponibilidade hídrica, geralmente, não há prejuízos (Pires et al., 2003). Todavia, em situações de déficit hídrico, veranicos de comum ocorrência no Cerrado, a espécie mais agressiva pode trazer prejuízos à outra em consórcio. McWillian (1986) e Jefferies (1993) também relataram a importância da competição hídrica para os cultivos em geral, apontando a água como o fator mais limitante da distribuição e produtividade de espécies vegetais pelo mundo.

\section{CONCLUSÕES}

O maior desenvolvimento das plantas de cobertura se dá quando semeadas na profundidade de até $1 \mathrm{~cm}$.

$\mathrm{O}$ índice e tempo de emergência das plantas de cobertura foram reduzidos a partir da semeadura à $8 \mathrm{~cm}$ de profundidade.

Todas as plantas de cobertura, exceto a Brachiaria decumbens, apresentam viabilidade na emergência em semeadura, sobre a superfície do solo.

Em consórcio com culturas anuais, a semeadura das braquiárias deve ser em torno de $8 \mathrm{~cm}$ de profundidade, destacando-se as Brachiaria brizantha e Brachiaria decumbens.

O Panicum maximum não é recomendado para consorciação com culturas anuais.

\section{AGRADECIMENTOS}

Á AGRISUS e CAPES pelo apoio financeiro e concessão de Bolsa de Mestrado.

\section{REFERÊNCIAS BIBLIOGRÁFICAS}

ALTMANN, N. Como iniciar em plantio direto: $2^{\mathrm{a}}$ parte. In: LARA-CABEZAS, W.R.; FREITAS, P.L. Plantio direto na integração lavoura-pecuária. Uberlândia: UFU, 2001. p.217-233.

ALVES, E.U.; BRUNO, R.L.A.; OLIVEIRA, A.P. de; ALVES, A.U.; PAULA, R.C. de. Influência do tamanho e da procedência de sementes de Mimosa caesalpiniifolia Benth. sobre a germinação e vigor. Revista Árvore, Viçosa, v.29, n.6, p.877-885, 2005.

CERETTA, C.A.; BASSO, C.J.; HERBES, M.G.; POLLETO, N.; SILVEIRA, M.J. Produção e decomposição de fitomassa de plantas invernais de cobertura de solo em milho sob diferentes manejos da adubação nitrogenada. Ciência Rural, Santa Maria, v.32, p.49-54, 2002. 
GARCIA, R.; ROCHA, F.C.; BERNALDINO, R.S.; GOBBI, K.F. Forrageiras utilizadas no sistema agricultura pecuária. In: ZAMBOLIM, L.; SILVA, A.A.; AGNES, H.L. (Ed.). Manejo integração: integração agricultura-pecuária. Viçosa, MG: UFV, 2004. p.331351.

JEFFERIES, R.A. Cultivares responses to water stress en potato: effects of shoot ans roots. New Phytologist, Oxford, v.123, p.491-498, 1993.

KLUTHCOUSKI, J.; AIDAR, H. Implantação, condução e resultados obtidos com o sistema Santa-fé. In: KLUTHCOUSKI, J.; AIDAR, H.; STONE, L.F. (Eds.). Integração lavoura-pecuária. Santo Antonio de Goiás: Embrapa Arroz e Feijão, 2003. p.407-441.

LARA-CABEZAS, W.A.R. Sobressemeadura com sementes de milheto revestidas no Triângulo Mineiro, MG: estudo preliminar. Revista Plantio Direto, Passo Fundo, n.79, p.16-18, 2004.

MCWILLIAN, J.R. The national and international importance of drought and salinity effects on agricultural production. Australian Journal of Plant Physiology, Melbourne, v.35, n.1, p.1-13, 1986.

MENEZES, L.A.S.; LEANDRO, W.M. Avaliação de espécies de coberturas do solo com potencial de uso em sistema de plantio direto. Pesquisa Agropecuária Tropical, Goiânia, v.34, n.3, p.173-180, 2004.

MIRANDA, P.R.M.; FERRAZ, I.D.K. Efeito da temperatura na germinação de sementes e morfologia da plântula de Maquira sclerophylla (Ducke) CC Berg. Revista Brasileira de Botânica, São Paulo, v.22, n.2, p.303-307, 1999.

MODOLO, A.J.; FERNANDES, H.C.; SCHAEFER, C.E.G.; SILVEIRA, J.C.M. da. Efeito da compactação do solo sobre a emergência de plântulas de soja em sistema plantio direto. Ciência e Agrotecnologia, Lavras, v.32, n.4, p.1259-1265, jul./ago., 2008.

OLIVEIRA, I.P. de; KLUTHCOUSKI, J.; YOKOYAMA, L.P.; DUTRA, L.G.; PORTES, T. de A.; SILVA, A.E. da; PINHEIRO, B. da S.; FERREIRA, E.; CASTRO, E. da M.; GUIMARÃES, C.M.; GOMIDE, J. de C.; BALBINO, L.C.
Sistema Barreirão: recuperação/renovação de pastagens degradadas em consórcio com culturas anuais. Goiânia: Embrapa-CNPAF, 1996. 87p. (EmbrapaCNPAF. Documentos, 64).

PACHECO, L.P.; PIRES, F.R.; MONTEIRO, F.P.; PROPCÓPIO, S.O.; ASSIS, R.L.; CARMO, M.L.; PETTER, F.A. Desemprnho de plantas de cobertura em sobressemeadura na cultura da soja. Pesquisa Agropecuária Brasileira, Brasília, v.43, n.7, p.815-823, 2008.

PACHECO, L.P.; PIRES, F.R.; MONTEIRO, F.P.; PROCÓPIO, S.O.; ASSIS, R.L.; SILVA, G.P.; CARGNELUTTI FILHO, A.; CARMO, M.L.; PETTER, F.A. Emergência e crescimento de plantas de cobertura em função da profundidade de semeadura. Semina:

Ciências Agrárias, Londrina, v.30, n.2, p.305-314, 2009.

PIRES, F.R.; SOUZA, C.M.; QUEIROZ, D.M.; MIRANDA, G.V.; GALVÃO, J.C.C. Alteração de atributos químicos do solo e estado nutricional e características agronômicas de plantas de milho, considerando as modalidades de calagem em plantio direto. Revista Brasileira de Ciência do Solo, Viçosa, v.27, n.1, p.121131, 2003.

PORTELLA, J.A.; SATLER, A.; FAGANELLO, A. Índice de emergência de plântulas de soja e de milho em semeadura direta no Sul do Brasil. Engenharia Agrícola, Jaboticabal, v.17, n.2, p.71-78, 1997.

PORTES, T.A.; CARVALHO, S.I.C.; OLIVEIRA, I.P.; KLUTHCOUSKI, J. Análise do crescimento de uma cultivar de braquiária em cultivo solteiro e consorciado com cereais. Pesquisa Agropecuária Brasileira, Brasília, v.35, n.7, p.1349- 1358, 2000.

SILVA, A.C.; FERREIRA, L.R.; SILVA, A.A.; BELO, A.F.; SEDIYAMA, C.S. Caracteres morfológicos de soja e braquiária consorciadas. Ciência Rural, Santa Maria, v.35, n.2, p.277-283, 2005.

SILVA, A.C.; FERREIRA, L.R.; SILVA, A.A.; PAIVA, T.W.B.; SEDIYAMA, C.S. Efeitos de doses reduzidas de fluazifop-p-butil no consórcio entre soja e Brachiaria brizantha. Planta Daninha, Rio de Janeiro, v.22, n.3, p.429-435, 2004. 